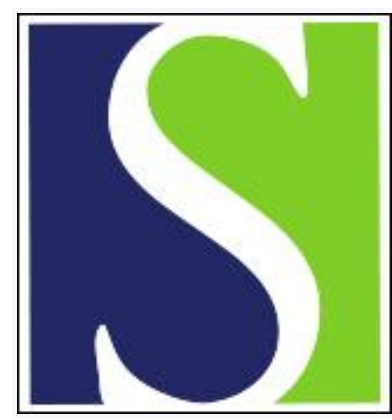

Scand J Work Environ Health 2011;37(6):551-555

https://doi.org/10.5271/sjweh.3191

Published online: 27 Aug 2011, Issue date: Nov 2011

Mental distress among shift workers in Norwegian offshore petroleum industry - relative influence of individual and psychosocial work factors

by Ljoså CH, Tyssen R, Lau B

Affiliation: National Institute of Occupational Health, PB 8149 Dep, NO-0033 Oslo, Norway. cha@stami.no

Refers to the following texts of the Journal: 2009;35(5):361-367

2006;32(6):443-462 2004;30(2):149-156

Key terms: individual work factor; mental disorder; mental distress; mental health; neuroticism; night work; Norway; petroleum industry; psychosocial work factor; shift work; shift work locus of control; shift work-home interference

This article in PubMed: www.ncbi.nlm.nih.gov/pubmed/21874209 


\title{
Mental distress among shift workers in Norwegian offshore petroleum industry - relative influence of individual and psychosocial work factors
}

\author{
by Cathrine Haugene Ljoså, MSc, ${ }^{1}$ Reidar Tyssen, MD, ${ }^{2}$ Bjørn Lau, PhD ${ }^{1}$
}

\begin{abstract}
Ljoså CH, Tyssen R, Lau B. Mental distress among shift workers in Norwegian offshore petroleum industry - relative influence of individual and psychosocial work factors. Scand J Work Environ Health. 2011;37(6):551-555. doi:10.5271/sjweh.3191
\end{abstract}

Objective This study aimed to investigate the association between individual and psychosocial work factors and mental distress among offshore shift workers in the Norwegian petroleum industry.

Methods All 2406 employees of a large Norwegian oil and gas company, who worked offshore during a two-week period in August 2006, were invited to participate in the web-based survey. Completed questionnaires were received from 1336 employees (56\% response rate). The outcome variable was mental distress, assessed with a shortened version of the Hopkins Symptom Checklist (HSCL-5). The following individual factors were adjusted for: age, gender, marital status, and shift work locus of control. Psychosocial work factors included: night work, demands, control and support, and shift work-home interference.

Results The level of mental distress was higher among men than women. In the adjusted regression model, the following were associated with mental distress: (i) high scores on quantitative demands, (ii) low level of support, and (iii) high level of shift work-home interference. Psychosocial work factors explained $76 \%$ of the total explained variance (adjusted $\mathrm{R}^{2}=0.21$ ) in the final adjusted model.

Conclusions Psychosocial work factors, such as quantitative demands, support, and shift work-home interference were independently associated with mental distress. Shift schedules were only univariately associated with mental distress.

Key terms mental disorder; mental health; neuroticism; night work; shift work-home interference; shift work locus of control.

Employees in the Norwegian offshore industry work long and intensive shifts. Their workplaces are installations in the North Sea where they are exposed to isolation, extreme weather, and risk of accidents. Although studies on shift work in the petroleum industry have increased in recent years, there is still a lack of knowledge about the effects of such working arrangements on mental health (1).

We presumed that the mental health of shift workers in the Norwegian petroleum industry would be affected by individual (2-7) and psychosocial work factors (8-21). We know from previous research on the general population that women report higher levels of anxiety and depressive symptoms than men $(22,23)$, and therefore, we hypothesized that the women in this study would report higher levels of mental distress. In addition to age and gender, we included structural support such as marital status. There is a lack of knowledge on the impact of such individual factors when psychosocial work factors such as night work, demands, control, support, and shift work-home interference are considered. Internal locus of control is considered to be a factor resembling coping or resilience in overcoming the effects of shift work (24-28), however, less is known about its effect among offshore shift workers (7). With this in mind, we investigated mental distress among offshore shift workers with the following research questions: (i) what is the association between mental distress and individual factors, such as age, gender, single marital status and shift work locus of control, and psychosocial work factors, such as night

1 National Institute of Occupational Health, Oslo, Norway.

2 Department of Behavioural Sciences, Institute of Basic Medical Sciences, Faculty of Medicine, University of Oslo, Oslo, Norway.

Correspondence to: Cathrine Haugene Ljoså, National Institute of Occupational Health, PB 8149 Dep, NO-0033 Oslo, Norway. [E-mail: cha@stami.no] 
work, demand, control, support and shift work-home interference? (ii) what is the relative influence of individual and psychosocial work factors on mental distress in a multiple regression model?

\section{Methods}

\section{Design and subjects}

All 2406 employees of a Norwegian petroleum company who worked offshore during a two-week period in August 2006 were invited to participate in the study. The research design used a web-based questionnaire (7), and complete questionnaires were received from 1336 employees (56\% response rate).

\section{Dependent variable}

Mental distress was assessed with a shortened version of the 25-item Hopkins Symptom Checklist (HSCL-5), which is a valid measure of anxiety and depressive symptoms (29-31). The HSCL-5 consists of five items, each with five response options, ranging from $1=$ "not at all" to 5="very much". The index was scored as the mean of the item scores. A scale of sum score was constructed, based on scores from 0-4, for comparison with other studies. High scores indicate high levels of mental distress.

\section{Independent variables}

Demographics. Participants were asked to state their marital status, and two categories were constructed based on the responses married/partner/cohabiting versus single.

Shift work locus of control. The original Shift work Locus of Control Scale (SHLOC) contains 20 items relating to four shift work-related areas, and the instrument has previously been validated (32). In this study, we used two items from the health dimension: (i) my physical well-being depends on how well I take care of myself when I work shifts, and (ii) if I feel ill when I am working shifts, it is because I have not been taking care of myself properly. The response categories went from $1=$ "strongly disagree" to $6=$ "totally agree".

Shift arrangements. On Norwegian installations, the most frequently worked pattern is two weeks working offshore, alternating with four weeks shore leave, and the standard shift duration is 12 hours $(7,33)$. As the period includes shore leave, we consider all the participants in this study to be shift workers. Participants were asked to specify the type of shift rotation they worked. Based on the responses two categories were constructed, namely day work (656 persons) and shift schedule including night work (680 persons).

Demand, control, support. The General Nordic Questionnaire for Psychological and Social Factors at Work (QPS Nordic) includes psychological and social factors at work that are related to well-being and health (34). In this study, we used QPS-scales of job demands and control and a scale concerning general social support from colleagues and supervisors; we added the term shift work to the questions. The three scales had five response categories ranging from $1=$ "very seldom or never" to $5=$ "very often or always". We used mean scores of each.

Shift work-home interference. Two questions were taken from the standard shift work index, regarding the effect of shift work on social and domestic life (28). The items were: "in general, to what extent does working shifts cause you problems with social life", and "in general, to what extent does working shifts cause you problems with domestic life?" with 5 response categories ranging from $1=$ "never" to $5=$ "always". We used a mean score for these two questions, since they correlated highly.

Table 1 provides an overview of the independent variables.

\section{Statistical analysis}

To study the variables and their relative impact on mental distress, we used block-wise linear regression analyses with a forced entry strategy. We included a block with individual vulnerability first (age, gender, marital status, and shift work locus of control); then we included two blocks of psychosocial work factors. All the variables were normally distributed, except mental distress. However, the residuals were normally distributed and did not affect the analysis.

\section{Ethics}

The research data were anonymous. The study was conducted in accordance with the World Medical Association Declaration of Helsinki and with permission from the Data Inspectorate of Norway.

\section{Results}

The mental distress mean sum score was 3.1 [standard deviation (SD) 3.5] for men and 2.4 (SD 3.2) for women.

Table 2 shows the individual and psychosocial work factors that were associated with mental distress. 
Table 1. Number, percentage, minimum/maximum (min/max) scores, range, mean and standard deviation (SD) of the dependent and the independent variables.

\begin{tabular}{|c|c|c|c|c|c|c|}
\hline & N & $\%$ & $\operatorname{Min} / \max$ & Range & Mean & SD \\
\hline Mental distress & 1001 & & $1-5$ & $1-4.4$ & 1.6 & 0.7 \\
\hline $\begin{array}{l}\text { Age group } \\
20-29 \\
30-39 \\
40-49 \\
50-59 \\
>60\end{array}$ & $\begin{array}{r}85 \\
275 \\
499 \\
415 \\
62\end{array}$ & $\begin{array}{r}6 \\
21 \\
37 \\
31 \\
5\end{array}$ & & $20-64$ & 45.1 & 9.6 \\
\hline $\begin{array}{l}\text { Gender } \\
\text { Women } \\
\text { Men }\end{array}$ & $\begin{array}{r}224 \\
1112\end{array}$ & $\begin{array}{l}17 \\
83\end{array}$ & & & & \\
\hline $\begin{array}{l}\text { Marital status } \\
\text { Married } \\
\text { Single }\end{array}$ & $\begin{array}{r}1134 \\
144\end{array}$ & $\begin{array}{l}89 \\
11\end{array}$ & & & & \\
\hline $\begin{array}{l}\text { Individual factor } \\
\text { Shift work locus of control }\end{array}$ & 1244 & & $1-6$ & $1-6$ & 3.8 & 1.0 \\
\hline $\begin{array}{l}\text { Shift schedule } \\
\text { Day work } \\
\text { Shift schedules including night work }\end{array}$ & $\begin{array}{l}656 \\
680\end{array}$ & $\begin{array}{l}49 \\
51\end{array}$ & & & & \\
\hline $\begin{array}{l}\text { Psychosocial work factors } \\
\text { Quantitative demands } \\
\text { Decisional demands } \\
\text { Control } \\
\text { Support } \\
\text { Shift work-home interference }\end{array}$ & $\begin{array}{r}1295 \\
1295 \\
1138 \\
982 \\
1253\end{array}$ & & $\begin{array}{l}1-5 \\
1-5 \\
1-5 \\
1-5 \\
1-5\end{array}$ & $\begin{array}{r}1.5-5 \\
1-5 \\
1-5 \\
1-5 \\
1-5\end{array}$ & $\begin{array}{l}3.3 \\
3.5 \\
3.3 \\
3.4 \\
2.6\end{array}$ & $\begin{array}{l}0.6 \\
0.6 \\
0.8 \\
0.9 \\
0.9\end{array}$ \\
\hline
\end{tabular}

\section{Blockwise multiple regression analyses}

In the first model, we entered the individual factors; low scores on locus of control were significantly associated with mental distress. In block 2, the shift work arrangements lost their significance when adjusted for individual factors. In block 3, we entered other psychosocial work factors. Shift work locus of control was no longer significantly associated with mental distress, whereas high scores on quantitative demands, low scores on social support, and in addition high scores on shift work home-interference were all significantly associated with mental distress.

To control for individual vulnerability that may affect the self-reported measures, we included neuroticism personality trait that resembles negative affectivity (3) in an additional model (not shown in table 2). This did not affect any of the adjusted factors; those who proved to be significant - before neuroticism was included in the adjusted analysis - remained significant in this additional model.

\section{Relative influence}

The final model in table 2 explained $21 \%$ of the variance in mental distress in this study. Of this variance, the individual and psychosocial work factors contributed $24 \%$ and $76 \%$, respectively, of the total explained variance of mental distress in our model.

\section{Discussion}

A major finding is that psychosocial work factors, such as quantitative demands, support, and shift work-home interference, were independently associated with mental distress; these factors contributed to a large majority of the total explained variance. Contrary to what we expected, shift schedules were only univariately associated with mental distress. This is partly in accordance with Bara et al's study (35). They only found a weak association between irregular work hours and mental distress. Somewhat unexpectedly, we found that men reported more mental distress than women, although the effect of gender disappeared when we controlled for the other individual variables.

The effect of shift work-home interference is one of the strongest in our analyses. Previously, we found that only a few participants of this population reported that their shift schedule affected their social and domestic/ family life (7). This may imply that shift work-home interference is strongly related to mental distress for those few affected by problems with family and social life.

We found that both high scores on quantitative demands and low scores on social support were associated with mental distress among the petroleum offshore workers. To our knowledge, this is the first study to investigate the role of psychosocial work factors, controlling for individual factors, among selected off- 
Table 2. Associations between individual and psychosocial work factors and mental distress (dependent variable) in a linear regression

\begin{tabular}{|c|c|c|c|c|c|}
\hline \multirow[t]{2}{*}{$\begin{array}{l}\text { Blocks entered in the multiple analyses } \\
\text { (forced entry) }\end{array}$} & \multicolumn{2}{|c|}{ Unadjusted analyses } & \multicolumn{2}{|c|}{$\begin{array}{c}\text { Adjusted analyses } \\
\text { Model } 3 \text { (all } 3 \text { blocks included) }\end{array}$} & \multirow[t]{2}{*}{$\begin{array}{l}\text { Adjusted } R^{2} \text { (block } \\
\text { wise cumulative) }\end{array}$} \\
\hline & $\beta$ & $95 \% \mathrm{Cl}$ & $\beta$ & $95 \% \mathrm{Cl}$ & \\
\hline Block 1 & & & & & 0.05 \\
\hline Age & 0.00 & $-0.04-0.04$ & -0.03 & $-0.08-0.01$ & \\
\hline Gender & $-0.14^{a}$ & $-0.25--0.02$ & -0.09 & $-0.21-0.03$ & \\
\hline Single marital status & 0.06 & $-0.07-0.19$ & 0.13 & $0.00-0.26$ & \\
\hline Shift work locus of control & $-0.15^{c}$ & $-0.19--0.11$ & -0.03 & $-0.08-0.01$ & \\
\hline Block 2 & & & & & 0.05 \\
\hline Shift schedules including night work & $0.12^{b}$ & $0.04-0.21$ & 0.01 & $-0.09-0.11$ & \\
\hline Block 3 & & & & & 0.21 \\
\hline Quantitative demands & $0.23^{c}$ & $0.15-0.30$ & $0.17^{c}$ & $0.09-0.26$ & \\
\hline Decisional demands & $0.15^{c}$ & $0.08-0.21$ & -0.02 & $-0.10-0.05$ & \\
\hline Control & $-0.14^{c}$ & $-0.19--0.08$ & -0.04 & $-0.10-0.03$ & \\
\hline Support & $-0.21^{c}$ & $-0.26--0.16$ & $-0.11^{c}$ & $-0.17--0.06$ & \\
\hline Shift work home interference & $0.32^{c}$ & $0.28-0.37$ & $0.28^{c}$ & $0.22-0.34$ & \\
\hline
\end{tabular}

a $P<0.05$

b $P<0.005$

c $P<0.001$

shore workers. Our findings are in keeping with a meta-analysis that found a risk of mental disorders for those with high demands and low decision latitude (19). Further, several studies have found a significant association between social support and mental health (19).

\section{Strengths and weaknesses}

This is a large-sized study, where all employees were invited to participate. Despite a somewhat low response rate, we believe the sample to be relatively unbiased, but there were more dropouts among women than men. Furthermore, the healthy worker effect may play a role, and adjustment to shift work-related problems may be a confounder (36).

We controlled for negative affectivity that represents a problem in all self-reported stress research (3). This strengthens the validity of our findings.

As this study is cross-sectional, we cannot infer anything about causality, and gender and age are the only two factors where reverse causation can be ruled out.

The present study points to the importance of psychosocial work factors also in a highly selected sample of petroleum offshore workers.

\section{Acknowledgments}

The research described in this paper was sponsored by the Research Council of Norway, as part of the Petromaks program (Optimal Management of Petroleum Resources).

\section{References}

1. Donnelly R. The offshore industry: overview. Occup Med. 2009;59:296-7. doi:10.1093/occmed/kqp073.

2. Bildt C, Michelsen H. Gender differences in the effects from working conditions on mental health; a 4-year follow-up. Int Arch Occup Environ Health. 2002;75:252-8. doi:10.1007/ s00420-001-0299-8.

3. Depue RA, Monroe SM. Conceptualization and measurement of human disorder in life stress research: the problem of chronic disturbance. Psychol Bull. 1986;99:36-51. doi:10.1037/0033-2909.99.1.36.

4. Jansen NWH, von Amelsvoort LGPM, Kristensen TS, van der Brandt PA, Kan IJ. Work schedules and fatigue: a prospective cohort study. Occup Environ Med. 2003;60:147-53.

5. Kandolin I. Burnout of female and male nurses in shiftwork. Ergon 1993;36:141-7. doi:10.1080/00140139308967865.

6. Åkerstedt T. Shift work and disturbed sleep/wakefulness. Occup Med. 2003;53:89-94. doi:10.1093/occmed/kqg046.

7. Ljosa CH, Lau B. Shiftwork in the Norwegian petroleum industry: overcoming difficulties with family and social life - a cross sectional study. J Occup Med Toxicol. 2009;4:22. doi:10.1186/1745-6673-4-22.

8. Nagashima S, Suwazono Y, Okubo Y, Uetani M, Kobayashi E, Kido $\mathrm{T}$ et al. Working hours and mental and physical fatigue in Japanese workers. Occup Med. 2007;57:449-52. doi:10.1093/ occmed/kqm047.

9. Geiger-Brown J, Muntaner C, Lipscomb J, Trinkoff A. Demanding work schedules and mental health in nursing assistants working in nursing homes. Work Stress. 2004;18:292-304. doi:10.1080/02678370412331320044.

10. Jamal M. Burnout, stress and health of employees on nonstandard work schedules: a study of Canadian workers. Stress 
Health. 2004;20:113-9. doi:10.1002/smi.1012.

11. Bussing A. Social tolerance of working time scheduling in nursing. Work Stress. 1996;10:238-50. doi:10.1080/02678379608256803.

12. Trinkoff AM, Storr CL. Work schedule characteristics and substance use in nurses. Am J Ind Med. 1998;34:266-71. doi:10.1002/(SICI)1097-0274(199809)34:3<266::AIDAJIM9>3.0.CO;2-T.

13. Hayasaka Y, Nakamura K, Yamamoto M, Sasaki S. Work environment and mental health status assessed by the general health questionnaire in female Japanese doctors. Ind Health. 2007;45:781-6. doi:10.2486/indhealth.45.781.

14. Harada H, Suwazono Y, Sakata K, Okubo Y, Oishi M, Uetani $\mathrm{M}$ et al. Three-shift system increases job-related stress in Japanese workers. J Occup Health. 2005;47:397-404. doi:10.1539/joh.47.397.

15. Kaneko SY, Maeda T, Sasaki A, Sato A, Tanaka K, Kobayashi T et al. Effect of shift work on mental state of factory workers. Fukushima J Med Sci .2004;50:1-9.

16. van Amelsvoort LG, Jansen NW, Swaen GM, van den Brandt PA, Kant I. Direction of shift rotation among three-shift workers in relation to psychological health and work-family conflict. Scand J Work Environ Health. 2004;30:149-56.

17. Karasek RA. Job Demands, Job Decision Latitude, and Mental Strain - Implications for Job Redesign. Administrative Science Quarterly. 1979;24:285-308. doi:10.2307/2392498.

18. van der Doef M, Maes S. The Job Demand-Control(Support) model and psychological well-being: a review of 20 years of empirical research. Work Stress. 1999;13:87-114. doi:10.1080/026783799296084.

19. Stansfeld S, Candy B. Psychosocial work environment and mental health - a meta-analytic review. Scand J Work Environ Health. 2006;32:443-62.

20. Wang JL. Perceived work stress, imbalance between work and family/personal lives, and mental disorders. Soc Psychiatry Psychiatr Epidemiol. 2006;41:541-8. doi:10.1007/s00127006-0058-y

21. Ross JK. Offshore industry shift work--health and social considerations. Occup Med. 2009;59:310-5. doi:10.1093/ occmed/kqp074

22. Sandanger I, Nygard JF, Ingebrigtsen G, Sorensen T, Dalgard OS. Prevalence, incidence and age at onset of psychiatric disorders in Norway. Soc Psychiatry Psychiatr Epidemiol. 1999;34:570-9. doi:10.1007/s001270050177

23. Kessler RC. Epidemiology of women and depression. J Affect Disord. 2003;74:5-13. doi:10.1016/S0165-0327(02)00426-3
24. Smith L, Mason C. Shiftwork locus of control effects in police officers. J Hum Ergol. 2001;30:217-22.

25. Smith L, Norman P, Folkard S. Predicting shiftwork-related outcomes: shiftwork locus of control and circadian type. J Hum Ergol. 2001;30:59-64.

26. Smith L, Tanigawa T, Takahashi M, Mutou K, Tachibana N, Kage Y et al. Shiftwork locus of control, situational and behavioural effects on sleepiness and fatigue in shiftworkers. Ind Health. 2005;43:151-70. doi:10.2486/indhealth.43.151

27. Takahashi M, Tanigawa T, Tachibana N, Mutou K, Kage Y, Smith L et al. Modifying effects of perceived adaptation to shift work on health, wellbeing, and alertness on the job among nuclear power plant operators. Ind Health. 2005;43:171-8. doi:10.2486/indhealth.43.171.

28. Barton J, Spelten E, Totterdell P, Smith L, Folkard S, Costa G. The Standard Shiftwork Index - A Battery of Questionnaires for Assessing Shiftwork-Related Problems. Work Stress 1995;9:4-30. doi:10.1080/02678379508251582

29. Derogatis LR, Lipman RS, Rickels K, Uhlenhuth EH, Covi L. The Hopkins Symptom Checklist (HSCL): a self-report symptom inventory. Behav Sci. 1974; 19:1-15.

30. Strand BH, Dalgard OS, Tambs K, Rognerud M. Measuring the mental health status of the Norwegian population: A comparison of the instruments SCL-25, SCL-10, SCL5 and MHI-5 (SF-36). Nord J Psych. 2003;57:113-8. doi:10.1080/08039480310000932.

31. Tambs K, Moum T. How Well Can A Few Questionnaire Items Indicate Anxiety and Depression. Acta Psych Scand 1993;87:364-7. doi:10.1111/j.1600-0447.1993.tb03388.x.

32. Smith L, Spelten E, Norman P. Shiftwork locus of control: Scale development. Work Stress. 1995;9:219-26. doi:10.1080/02678379508256557.

33. Parkes KR. Working hours in the offshore petroleum industry. Oxford, UK: University of Oxford. Department of Experimental Psychology, 2007.

34. Dallner M, Elo A-L, Gamberale F, Hottinen V, Knardah $\mathrm{S}$, Lindstrom $\mathrm{K}$ et al. Validation of the General Nordic Questionnaire for Psychological and Social Factors at Work. Copenhagen: Nordic Council of Ministers, Nord; 2000:12.

35. Bara A-C, Arber S. Working shifts and mental health - findings from the British Household Panel Survey (1995-2005). Scand J Work Environ Health. 2009;35(5):361-367.

36. Spelten E, Barton J, Folkard S. Have We Underestimated Shiftworkers Problems - Evidence from A Reminiscence Study. Ergon. 1993;36:307-12. doi:10.1080/00140139308967886.

Received for publication: 7 August 2010 
